\title{
Intratesticular distribution of testosterone in rats and the relationship to the concentrations of a peptide that stimulates testosterone secretion
}

\author{
R. M. Sharpe and J. M. S. Bartlett \\ MRC Reproductive Biology Unit, Centre for Reproductive Biology, 37 Chalmers Street, \\ Edinburgh $E H 39 E W, U . K$.
}

\begin{abstract}
Summary. Methods have been established and validated for quantitative assessment of the distribution of testosterone in the testis, by measurement of testosterone concentrations in whole testis, in isolated seminiferous tubules and in testicular interstitial fluid. These measurements were made in individual rats injected $2-40 \mathrm{~h}$ previously with saline $(0.9 \% \mathrm{NaCl})$ or a potent antiserum to ovine $\mathrm{LH}$. Testosterone concentrations in interstitial fluid and seminiferous tubules were closely correlated $(r=+0.98 ; n=60)$ and their relationship was log linear over a 200-fold range. However, although the concentrations of testosterone in interstitial fluid and seminiferous tubules decreased progressively with time after LH antiserum injection, this decrease was far more pronounced for interstitial fluid. In association with this change there was a significant increase in the amounts of a locally-produced factor in interstitial fluid which stimulates basal and hCG-stimulated testosterone production by isolated purified Leydig cells. This increase was reversed by injection of hCG but not by peripheral injection of a dose $(20 \mathrm{mg})$ of testosterone propionate which restored normal intratesticular concentrations of testosterone. It is concluded that the tubular 'conservation' of testosterone, which occurs as interstitial fluid levels of this steroid decrease, may be a consequence of restricted diffusion of testosterone out of the tubules, but is also associated with increased amounts of a peptide stimulator of testosterone production.
\end{abstract}

\section{Introduction}

Mammalian spermatogenesis is driven and maintained by testosterone, which is produced by the Leydig cells and acts on the Sertoli cells. The available evidence suggests that although spermatogenesis may be maintained qualitatively in hypophysectomized rats in the presence of 10 $20 \%$ of normal intratesticular levels of testosterone (Ahmad, Haltmeyer \& Eik-Nes, 1973; Cunningham \& Huckins, 1979; Buhl, Cornette, Kirton \& Kuan, 1982), quantitative maintenance of spermatogenesis can only be achieved by restoration of intratesticular levels of testosterone at the upper end of the normal range (Stevens \& Steinberger, 1983). Mechanisms that permit the local control of intratesticular testosterone levels may therefore exist (Sharpe, 1984). However, virtually nothing is known about how testosterone drives spermatogenesis (reviewed by Sharpe, 1983).

Studies on isolated seminiferous tubules from the adult rat testis have demonstrated considerable changes in various aspects of Sertoli cell function depending on the stage of the spermatogenic cycle (reviewed by Parvinen, 1982; Sharpe, 1983), and the testosterone content of the tubules is highest at stages VII-VIII (Parvinen \& Ruokonen, 1982), which is the acutely androgen-dependent period of the cycle (Sharpe, 1983). Such findings prompted us to investigate whether comparison of testosterone levels in the seminiferous tubules with those in the interstitial fluid bathing the outside of the tubules (and from which the tubules derive their testosterone), 
would provide further insight into the local control of intratesticular testosterone levels, as well as providing basic information on how testosterone is normally distributed between these two compartments.

\section{Materials and Methods}

Animals, treatments and collection of tissues. Sprague-Dawley rats aged 75-90 days from our own colony were used for all experiments and were housed under conventional conditions. Four experiments were undertaken initially to validate the procedures used in this study. Experiment 1 was performed to establish the accuracy of the methods used for measurement of testosterone concentrations in testicular interstitial fluid. Groups of rats were injected subcutaneously with 0.7 $\mathrm{ml} 0.9 \%$ (w/v) $\mathrm{NaCl}$ (controls), $10 \mu \mathrm{g}$ ovine LH (NIH-LH-S24) in $0.7 \mathrm{ml} 0.9 \% \mathrm{NaCl}$ or $0.7 \mathrm{ml}$ of a highly potent rabbit antiserum to ovine LH (R-31), and killed 2 or $5 \mathrm{~h}$ later. Characteristics of the LH antiserum have been described elsewhere (Sharpe \& Fraser, 1983). In addition to these treatments each rat had received an earlier subcutaneous injection of $5 \times 10^{6}$ c.p.m. ${ }^{125} \mathrm{I}$-labelled bovine serum albumin (BSA, fraction V: Sigma, St Louis, MO, U.S.A.) in $0.2 \mathrm{ml} 0.9 \% \mathrm{NaCl}$, this treatment being given $8 \mathrm{~h}$ before the animals were killed to allow equilibration of the levels of radiolabelled BSA in serum and testicular interstitial fluid (Setchell \& Sharpe, 1981; Sharpe \& Cooper, 1983). Animals were killed with solid $\mathrm{CO}_{2}$-generated $\mathrm{CO}_{2}$, and blood was collected from the trunk. Both testes were dissected out and blotted free of blood, and the ${ }^{125}$ I content was measured in a gamma counter. The left testis was then decapsulated carefully and left to stand at $4^{\circ} \mathrm{C}$ for 30-60 min in a glass scintillation vial. The interstitial fluid that had drained from the testis during this period was aspirated in measured amounts and its ${ }^{125} \mathrm{I}$ content was assessed before processing for testosterone measurement as described below. Identical procedures were used for the non-decapsulated right testis from which interstitial fluid was collected over $16-20 \mathrm{~h}$ at $4^{\circ} \mathrm{C}$ as detailed previously (Sharpe, 1981; Sharpe \& Cooper, 1983). The ${ }^{125}$ I concentration in serum from each animal was also measured and compared to that for the collected interstitial fluid. This permitted calculation of the total interstitial fiuid volume ( = the albumin space) of the testis (Setchell \& Sharpe, 1981; Sharpe \& Cooper, 1983). After interstitial fluid collection, the right testis was decapsulated and this and the decapsulated left testis and interstitial fluids were stored at $-20^{\circ} \mathrm{C}$ for subsequent extraction and measurement of testosterone.

Experiment 2 was performed to assess whether measurement of testosterone in isolated seminiferous tubules and interstitial fluid from individual animals provided an accurate measure of steroid concentrations in relation to the total testicular content of testosterone. Groups of rats were injected with $0.7 \mathrm{ml}$ vehicle or antiserum to $\mathrm{LH}$ and killed at 20 or $40 \mathrm{~h}$ after injection. The testes were dissected out, weighed, and the left testis immediately decapsulated and stored at $-20^{\circ} \mathrm{C}$ for subsequent extraction. The contralateral testis was decapsulated and interstitial fluid collected over the next $45-60 \mathrm{~min}$ at $4^{\circ} \mathrm{C}$ as described in Exp. 1; this fluid was stored at $-20^{\circ} \mathrm{C}$ for subsequent measurement of testosterone. Seminiferous tubules were then isolated from the decapsulated testis by teasing at $4^{\circ} \mathrm{C}$ as described below.

Experiments 3 and 4 were undertaken to assess the effect of the method of seminiferous tubule isolation on the measured testosterone content and whether diffusion of testosterone from the tubules during isolation was an important factor in this respect. Leydig cell contamination of the isolated tubules was also assessed. For these studies rats were treated with $0.9 \% \mathrm{NaCl}$ or antiserum to $\mathrm{LH}$ as described above and killed $20 \mathrm{~h}$ later. In one group of treated animals, interstitial fluid was collected overnight from the right testis whilst seminiferous tubules were isolated immediately by teasing at $4^{\circ} \mathrm{C}$ from the decapsulated left testis as described below. In a second group, the procedures were identical except that the decapsulated left testis was first partly dissociated with collagenase during incubation for $5 \mathrm{~min}$ at $32^{\circ} \mathrm{C}$ in a shaking water bath as detailed previously (Sharpe \& Fraser, 1983), and the tubules then isolated. Assessment of the diffusion of intratubular 
testosterone and tubular contamination with Leydig cells was performed using teased tubules from saline-injected rats, and full procedural details are given below.

Induction of changes in the intratesticular distribution of testosterone and the relationship to amounts of a locally-produced stimulator of testosterone secretion. In Exp. 5, rats were injected subcutaneously with $0.7 \mathrm{ml}$ antiserum to $\mathrm{LH}$ and groups of animals were killed at 2, 4, 8, 24 or $40 \mathrm{~h}$ after injection; 3 groups of saline-injected control animals were killed at 4,24 or $40 \mathrm{~h}$ after treatment. For each animal, the paired testes were dissected out and tubules were isolated from the left testis by teasing at $4^{\circ} \mathrm{C}$. Interstitial fluid from the right testis of each animal was collected over $16 \mathrm{~h}$ at $4^{\circ} \mathrm{C}$ as described above. Its volume was measured during aspiration and $10 \mu \mathrm{l}$ were removed and diluted 1:20 with Medium 199 (Flow Laboratories, Irvine, U.K.) containing Hanks' salts and 20 mMHepes (Medium 199H) and stored at $-20^{\circ} \mathrm{C}$ for subsequent testosterone measurement. The remainder of the collected interstitial fluid was pooled within each treatment group and processed as described below for assessment of the amount of a locally-produced stimulator of testosterone secretion (Sharpe \& Cooper, 1984). After fluid collection, the right testis was decapsulated and stored at $-20^{\circ} \mathrm{C}$ for subsequent extraction. From this study it was therefore possible to assess the total testicular content of testosterone (tissue + total in collected interstitial fluid), the relative change in testosterone amounts in the tubules in relation to that in interstitial fluid, and to relate these data to the values in interstitial fluid of a locally-produced stimulator of Leydig cell testosterone secretion.

Experiment 6 evaluated in more detail the relationship between $\mathrm{LH}$ deprivation and the levels of the interstitial fluid factor described above. Groups of rats were injected with saline or antiserum to $\mathrm{LH}$ and killed at 4, 8, 20 or $40 \mathrm{~h}$ after injection. To assess whether the changes induced by $\mathrm{LH}$ deprivation were reversible, a further group of animals was injected with the LH antiserum: $20 \mathrm{~h}$ later the rats were injected subcutaneously with 150 i.u. hCG (Chorulon, Intervet, Cambridge, U.K.) in $0.2 \mathrm{ml} 0.9 \%(\mathrm{w} / \mathrm{v}) \mathrm{NaCl}$ and killed $20 \mathrm{~h}$ after this second treatment. The $\mathrm{LH}$ antiserum used for these studies shows only minor cross-reaction with hCG. After dissecting out the testes, interstitial fluid was collected from the left and right testes by the overnight $(16 \mathrm{~h})$ procedure. Fluid from both testes was then pooled and $10 \mu \mathrm{l}$ were removed for testosterone measurement as described in Exp. 5. The remaining interstitial fluid from individual rats was diluted with 2 volumes of Medium $199 \mathrm{H}$ and then stored at $-20^{\circ} \mathrm{C}$ until processed for assessment of its ability to stimulate testosterone secretion as described below.

Experiment 7 assessed whether restoration of normal intratesticular levels of testosterone by peripheral administration of the steroid was able to reverse the changes induced by LH deprivation. Three groups of rats were injected subcutaneously with (i) saline, (ii) LH antiserum or (iii) $\mathrm{LH}$ antiserum followed 20 and $28 \mathrm{~h}$ later by two injections of $10 \mathrm{mg}$ testosterone propionate (Sigma) in $0.2 \mathrm{ml}$ arachis oil. Rats were killed $40 \mathrm{~h}$ after their initial treatment and one testis was processed for overnight collection of interstitial fluid, whilst fluid from the contralateral testis was collected over $1 \mathrm{~h}$ at $4^{\circ} \mathrm{C}$ and the testis then used for isolation of seminiferous tubules. Interstitial fluid was processed as described in Exp. 6, and other procedures were as detailed below.

Seminiferous tubule dissections. All stages of the dissection procedure described below were performed on a trans-illuminated $1.27 \mathrm{~cm}(0.5 \mathrm{in})$ deep Perspex stage, mounted on a Leitz dissecting microscope, and through which ice-cold water was pumped continuously. Each decapsulated testis was placed in a plastic Petri dish containing ice-cold Medium $199 \mathrm{H}$ and teased gently apart to enable isolation of lengths of undamaged seminiferous tubules, which were then transferred to a second dish containing cold Medium 199H. Care was taken to exclude tubules with adherent interstitial/connective tissue. Only lengths of tubules in excess of $2 \mathrm{~cm}$ (approx. range 2-8 cm) were used, and when sufficient had been obtained, all but a thin film of the Medium 199H was aspirated and the dish was orientated over a transparent grid with 1,5 and $10 \mathrm{~mm}$ squares. Using watchmakers forceps, the tubules were aligned in parallel above the grid and cut into $0.5 \mathrm{~cm}$ lengths using a scalpel. For each testis, 4 separate collections of $20 \times 0.5 \mathrm{~cm}$ lengths were then removed by 
forceps and placed into glass tubes containing $0.2 \mathrm{ml}$ distilled water. These were stored at $-20^{\circ} \mathrm{C}$ until extracted for testosterone measurement as described below. Four collections of tubules per rat were dissected to minimize errors due to over-selection of tubules at different stages of the spermatogenic cycle (Parvinen \& Ruokonen, 1982). In the present study, the overall coefficient of variation for testosterone concentrations measured in the 4 tubule collections per rat was $10 \cdot 3 \pm$ $5.7 \%$ (mean \pm s.d., $n=75$, ranging from 1.5 to $24.3 \%$ ). In exp. 3 , identical procedures were used on collagenase-digested testes except that no teasing apart of the testis was necessary before tubule isolation.

For assessment of the diffusion of testosterone out of the tubules, collections of $20 \times 0.5 \mathrm{~cm}$ lengths of tubules were dissected and kept at $21^{\circ} \mathrm{C}$ in $2 \mathrm{ml} \mathrm{Medium} 199 \mathrm{H}$. At specified times the tubules were removed and placed in $0.2 \mathrm{ml}$ distilled water for subsequent extraction, whilst the incubation medium was also stored for extraction. Tubules dissected at time zero and placed in $0 \cdot 2$ $\mathrm{ml}$ distilled water served as initial controls.

For assessment of Leydig cell contamination tubules were dissected by teasing as above and triplicate groups of $20 \times 0.5 \mathrm{~cm}$ lengths were incubated for $16 \mathrm{~h}$ at $21^{\circ} \mathrm{C}$ in $0.3 \mathrm{ml} \mathrm{Medium} 199 \mathrm{H}$ containing $0.25 \%$ BSA and 345000 c.p.m. ${ }^{125}$ I-labelled hCG. Samples of Percoll-purified Leydig cells $\left(0 \cdot 1 \times 10^{6}\right)$, prepared as described below, were incubated in parallel under the same conditions. For both tubules and cells, non-specific binding was determined by parallel incubation in the presence of 100 i.u. unlabelled hCG (Chorulon, Intervet). Bound and free hormone were separated as described elsewhere (Sharpe \& Cooper, 1982).

Processing of testicular interstitial fluid and assessment of its ability to stimulate Leydig cell testosterone secretion in vitro. Interstitial fluid collected for measurement of its testosterone concentration was unprocessed apart from being diluted 1:20 with Medium 199H before storage at $-20^{\circ} \mathrm{C}$. For assessment of the ability of interstitial fluid to stimulate testosterone secretion in vitro, the fluid was diluted $1: 3$ with Medium $199 \mathrm{H}$ and steroids were removed by extracting twice with 20 $\mathrm{mg}$ charcoal $/ \mathrm{ml}$ (Norit A; Sigma) for $1 \mathrm{~h}$ at $21^{\circ} \mathrm{C}$; this removes $>95 \%$ of the testosterone (Sharpe \& Cooper, 1984). Extracted interstitial fluid from groups of rats (Exp. 5) or from individual rats (Exps $6 \& 7$ ) was then stored at $-20^{\circ} \mathrm{C}$ until tested for in-vitro bioactivity as described previously (Sharpe $\&$ Cooper, 1984). Briefly, $75 \mu$ of the extracted, diluted interstitial fluid were added to $0.05 \times 10^{6}$ Percoll-purified rat Leydig cells in plastic multiwell dishes (Nunc, Kamstrup, Denmark) in a final incubation volume of $250 \mu \mathrm{l}$. Therefore, the final concentration of interstitial fluid in the medium was $10 \%$, a level at which its effect on Leydig cell testosterone secretion is always greater than the presumed non-specific effects of charcoal-extracted rat serum (see Sharpe \& Cooper, 1984). Each sample of interstitial fluid was run in duplicate or triplicate and incubations were performed in the absence (Exp. 5) or presence (Exps 6 \& 7) of a maximally-stimulating concentration ( $5 \mathrm{nM}$ ) of hCG (Chorulon). Control wells contained $75 \mu \mathrm{l}$ charcoal-extracted Medium 199H instead of interstitial fluid. Incubations were for $5 \mathrm{~h}$ at $32^{\circ} \mathrm{C}$ under a humidified atmosphere of $5 \% \mathrm{CO}_{2}$ in air and other details were as described previously (Sharpe \& Cooper, 1984). All samples from any single experiment were run with the same preparation of Leydig cells.

Interstitial fluid causes dose-dependent stimulation of testosterone secretion by Leydig cells in vitro (Sharpe \& Cooper, 1984) and this was confirmed for the present study using pooled interstitial fluid from control rats and rats treated $20 \mathrm{~h}$ previously with anti-LH serum. However, because of the small volumes of fluid obtained from individual animals (50-70 $\mu 1 /$ testis) it was only possible to assess effects at a single dose level. Results have therefore been expressed simply as the increment in testosterone levels (ng/ $10^{6}$ cells) above the control (i.e. incubation in the absence of interstitial fluid) induced by addition of $10 \%$ interstitial fluid.

Testosterone measurements. Testosterone concentrations in Leydig cell incubation medium were assayed unextracted after appropriate dilution as described previously (Sharpe \& Fraser, 1983; Sharpe \& Cooper, 1984). Testosterone in interstitial fluid was also assayed without prior extraction (Sharpe \& Cooper, 1983), except in Exp. 1 in which the interstitial fluid was first extracted with 10 
volumes of hexane : diethyl ether $(4: 1, \mathrm{v} / \mathrm{v})$ to prevent interference from the injected ${ }^{125} \mathrm{I}$-labelled BSA.

Each collection of dissected seminiferous tubules in $0.2 \mathrm{ml}$ distilled water was sonicated for 1 min and then extracted with $3 \mathrm{ml}$ hexane : diethyl ether $(4: 1, \mathrm{v} / \mathrm{v})$ after addition of $\sim 2000$ c.p.m. $\left[{ }^{3} \mathrm{H}\right]$ testosterone to monitor for recovery, which ranged from 70 to $80 \%$. Testicular tissue was extracted essentially as described by de Jong, Hey \& van der Molen (1974), and the recovery of added $\left[{ }^{3} \mathrm{H}\right]$ testosterone ranged from 85 to $95 \%$. All extracted samples were dried under a stream of nitrogen and reconstituted for assay in $0.01 \mathrm{M}$-phosphate-buffered saline, $\mathrm{pH} 7 \cdot 4$, containing $5 \%$ gelatin.

Testosterone concentrations in Leydig cell incubation medium were assayed as described by Corker \& Davidson (1978), whilst all other samples were assayed in a double-antibody radioimmunoassay using ${ }^{125}$ I-labelled testosterone-3-carboxymethyloxine as tracer and an antiserum (No. 505) raised in sheep against the same testosterone conjugate. This antiserum cross-reacts $23 \%$ with dihydrotestosterone, $1.6 \%$ with androstenedione and $3.1 \%$ with oestrone but shows minimal $(<0.1 \%)$ cross-reaction with 15 other steroids which have been tested. Unextracted interstitial fluid and Leydig cell incubation medium and extracts of seminiferous tubules and whole testes gave displacement curves parallel to the testosterone standard, and values obtained for samples run in this assay and in the conventional $\left[{ }^{3} \mathrm{H}\right]$ testosterone-based assay (Corker \& Davidson, 1978) did not differ significantly $(P>0 \cdot 1)$ and showed strong overall correlation $(r=+0 \cdot 96 ; n=342)$. The limit of detection $\left(90 \% \mathrm{~B} / \mathrm{B}_{0}\right)$ of the assay was $11 \pm 3 \mathrm{pg}$ (mean \pm s.d., $n=173$ ) and the inter-assay coefficient of variation was $10.4 \%$.

Iodinations. hCG (NIAMDD-CR-19) and BSA (fraction V, Sigma) were iodinated using lactoperoxidase to specific activities of about 50 and $70 \mathrm{mCi} / \mathrm{mg}$. Testosterone-3-caroxymethyloxime was iodinated using chloramine-T and the reaction products extracted with ethyl acetate before separation by thin-layer chromatography (Kieselgel 60F254, Merck) using a solvent mixture of chloroform:methanol:acetic acid $(90: 10: 1$, by vol). The required peak was then eluted in ethanol and stored at $4^{\circ} \mathrm{C}$.

\section{Results}

\section{Comparison of rapid and overnight methods of testicular interstitial fluid collection (Exp. I)}

Irrespective of treatment or the actual concentration of testosterone in interstitial fluid, values for the rapid $(0 \cdot 5-1 \mathrm{~h})$ and overnight $(16-20 \mathrm{~h})$ methods did not differ significantly when applied to left and right testes, respectively (Table 1). Moreover, as judged by the ratio of the concentration of ${ }^{125} \mathrm{I}$-labelled BSA in interstitial fluid to that in serum, contamination of the interstitial fluid with seminiferous tubule fluid (from which BSA is excluded) was negligible for both methods of collection (Table 1). These results suggest that leakage of testosterone from the seminiferous tubules into the surrounding interstitial fluid is negligible during overnight storage at $4^{\circ} \mathrm{C}$, and that this method and the rapid method of fluid collection can be used interchangeably without affecting the accuracy of the results obtained for testosterone concentrations.

Calculation of the total testosterone present in interstitial fluid in relation to the total amount of testosterone in the testis revealed that after LH antiserum injection, when the total testosterone content was reduced to $<20 \%$ of control values, there was a significant change in the relative distribution of testosterone, with significantly less testosterone in the interstitial fluid compartment (Table 1).

Inter-compartmental distribution of testosterone in the testis (Exp. 2)

From the measured concentration of testosterone in seminiferous tubules isolated by teasing at $4^{\circ} \mathrm{C}$ from decapsulated testes, the total tubule content of testosterone per testis could be calculated. 
Table 1. Comparison of results obtained when testicular interstitial fluid (IF) was collected by a rapid $(0.5 \mathrm{~h})$ or overnight $(16-20 \mathrm{~h})$ method from the left and right testes, respectively, of rats loaded with ${ }^{125}$ I-labelled BSA (mean \pm s.d.)

\begin{tabular}{|c|c|c|c|}
\hline & \multicolumn{3}{|c|}{ Treatment group } \\
\hline & $\begin{array}{l}\text { Controls } \\
(\mathrm{N}=20)\end{array}$ & $\begin{array}{c}10 \mu g \text { LH }+2 h \\
(N=13)\end{array}$ & $\begin{array}{c}\text { Anti-LH }+5 \text { h } \\
(\mathrm{N}=9)\end{array}$ \\
\hline \multicolumn{4}{|l|}{ Testosterone level in IF $(\mathrm{ng} / \mathrm{ml})$} \\
\hline Rapid method & $475 \pm 269$ & $1361 \pm 415$ & $62 \pm 9$ \\
\hline Overnight method & $484 \pm 299$ & $1455 \pm 481$ & $57 \pm 35$ \\
\hline \multicolumn{4}{|l|}{ IF : serum ratio of ${ }^{125}$ I-labelled BSA } \\
\hline Rapid method & $1.04 \pm 0.10$ & $0.99 \pm 0.09$ & $1.05 \pm 0.11$ \\
\hline Overnight method & $1.00 \pm 0.13$ & $0.93 \pm 0.06$ & $1.03 \pm 0.06$ \\
\hline BSA space $(\mu \mathrm{l} /$ testis $)$ & $225 \pm 25$ & $229 \pm 17$ & $211 \pm 34$ \\
\hline Total IF testosterone/testis (ng)† & $162 \pm 43$ & $355 \pm 83$ & $20 \pm 3$ \\
\hline Total testosterone/testes (ng) & $596 \pm 172$ & $1222 \pm 403$ & $124 \pm 14$ \\
\hline $\begin{array}{l}\text { IF testosterone as \% of } \\
\text { total testis testosterone }\end{array}$ & $28 \cdot 0 \pm 5 \cdot 5$ & $29 \cdot 3 \pm 5 \cdot 4$ & $16 \cdot 4 \pm 3 \cdot 5^{*}$ \\
\hline
\end{tabular}

* $P<0.001$, when compared with values for the other 2 groups.

$\dagger$ Derived by multiplying the IF concentration of testosterone by the BSA space.

$\ddagger$ Derived by adding the testosterone removed in the collected IF to that remaining in the testis.

When this value was added to the calculated testosterone content of testicular interstitial fluid, the resultant values were not significantly different $(P>0.05)$ from the total testosterone content of the contralateral testis as measured after extraction (Table 2). This demonstrates (1) that most of the testosterone present in the testis is sequestered in the seminiferous tubules or is in interstitial fluid, and (2) that diffusion of testosterone out of the seminiferous tubules during the isolation procedure must have been minimal (see also below).

In rats injected with $\mathrm{LH}$-antiserum and in which there was the expected fall in testicular testosterone content, this reduction was far more pronounced for interstitial fluid testosterone concentrations ( $93-98 \%$ reduction) than for seminiferous tubule testosterone concentrations $(80 \%$ reduction), with the result that a significantly smaller proportion of the testicular content of testosterone was present in the interstitial fluid (Table 2). This confirms the results illustrated in Table 1.

Table 2. Distribution of testosterone in seminiferous tubules and testicular interstitial fluid (IF) in relation to the total testicular content of testosterone in control and LH-antiserum treated rats (mean \pm s.d.)

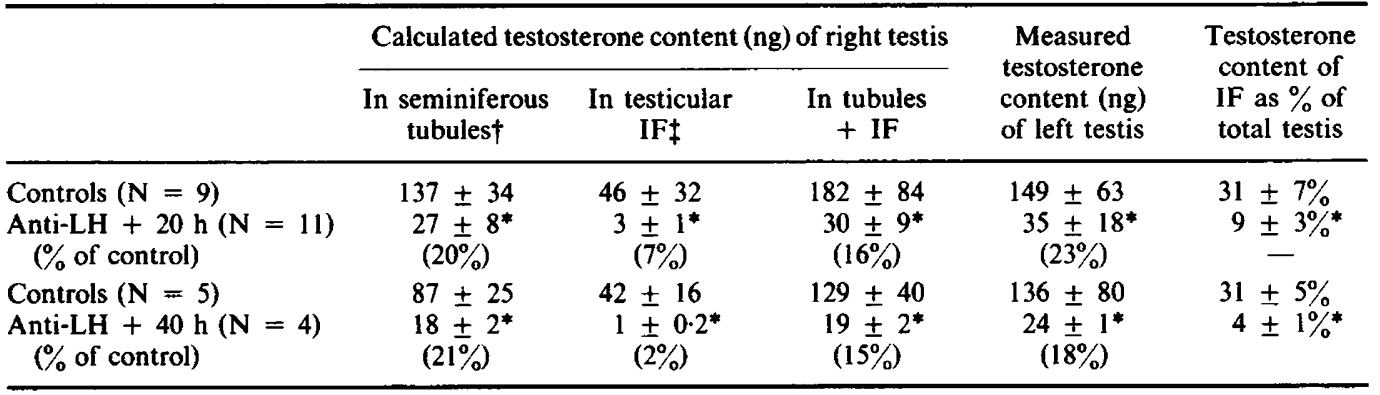

* $P<0.001$, compared with respective control group (Student's $t$ test).

$\dagger$ Assuming $1240 \mathrm{~cm}$ tubule/g testis (Wing \& Christensen, 1982).

$\ddagger$ Assuming that IF accounts for $12.5 \%$ of testicular weight (derived from the study illustrated in Table 1). 


\section{Validation of the measurement of seminiferous tubule testosterone concentrations (Exps 3 and 4)}

Although the results from Exps 1 and 2 suggested that diffusion of testosterone from the seminiferous tubules during isolation was minimal, this was tested further in the following way. Tubules were dissected by teasing at $4^{\circ} \mathrm{C}$ from decapsulated testes and the testosterone concentration was compared with that of tubules isolated from testes which had been dissociated by incubation for $5 \mathrm{~min}$ with collagenase at $32^{\circ} \mathrm{C}$. Results obtained by either method were comparable (Table 3), suggesting that the testosterone normally present in the seminiferous tubules does not readily diffuse outwards during short-term exposure to $32^{\circ} \mathrm{C}$, at least when the tubules are in long intact lengths. Confirmation that intratubular testosterone could diffuse outwards was obtained by teasing out tubules at $4^{\circ} \mathrm{C}$ and then incubating $20 \times 0.5 \mathrm{~cm}$ lengths for periods of 0,20 , 60 and $240 \mathrm{~min}$ at $21^{\circ} \mathrm{C}$. Compared with the time zero tubule testosterone concentration of $437 \pm$ $72 \mathrm{pg} / 10 \mathrm{~cm}$ (mean \pm s.d., $n=4$ ), after incubation for $20 \mathrm{~min}$ at $21^{\circ} \mathrm{C}$ values had decreased by over $50 \%(215 \pm 71 \mathrm{pg})$ and by 60 and $240 \mathrm{~min}$ had become virtually undetectable $(19 \pm 33$ and $<5$ $\mathrm{pg} / 10 \mathrm{~cm}$, respectively); these decreases were matched by corresponding increases in the testosterone detectable in the incubation medium.

Leydig cell contamination of the isolated seminiferous tubules did not contribute significantly to the measured testosterone content of the tubules as evidenced by the absence of significant $(P>$ $0 \cdot 1)$ specific binding of ${ }^{125} \mathrm{I}$-labelled hCG to isolated tubules (specific binding $200 \pm 215$ c.p.m. $/ 10$ $\mathrm{cm}$ ) when compared with Percoll-purified Leydig cells (specific binding $184800 \pm 3100$ c.p.m./10 cells).

Table 3. Comparison of testosterone levels in testicular interstitial fluid (IF) and isolated seminiferous tubules from teased or collagenase-digested testes (mean \pm s.d.)

\begin{tabular}{|c|c|c|c|c|}
\hline \multirow{2}{*}{$\begin{array}{l}\text { Treatment group } \\
\text { and method of } \\
\text { tubule preparation }\end{array}$} & \multirow[b]{2}{*}{$\begin{array}{l}\text { No. of } \\
\text { animals }\end{array}$} & \multicolumn{2}{|c|}{ Testosterone concentration } & \multirow{2}{*}{$\begin{array}{c}\text { Ratio of } \\
\text { testosterone } \\
\text { in tubules to } \\
\text { that in IF }\end{array}$} \\
\hline & & $\begin{array}{c}\text { Seminiferous } \\
\text { tubules }(\mathrm{pg} / 10 \mathrm{~cm})\end{array}$ & $\begin{array}{l}\text { Testicular } \\
\text { IF (ng/ml) }\end{array}$ & \\
\hline \multicolumn{5}{|l|}{ Teased tubules } \\
\hline Controls & 8 & $930 \pm 389$ & $530 \pm 302$ & $2 \cdot 0 \pm 0.6$ \\
\hline $\begin{array}{c}\text { Anti-LH }+20 \mathrm{~h} \\
(\% \text { of control })\end{array}$ & 5 & $\begin{array}{c}262 \pm 70^{*} \\
(28 \%)\end{array}$ & $\begin{array}{c}39 \pm 10^{*} \\
(7 \%)\end{array}$ & $\begin{array}{c}6.8+1.4^{*} \\
(340 \%)\end{array}$ \\
\hline \multicolumn{5}{|c|}{ Tubules from collagenase-digested testes } \\
\hline Controls & 5 & $894 \pm 198$ & $286 \pm 147$ & $3.7 \pm 1.4$ \\
\hline $\begin{array}{c}\text { Anti-LH }+20 \mathrm{~h} \\
(\% \text { of control })\end{array}$ & 6 & $\begin{array}{c}180 \pm 38 * \\
(20 \%)\end{array}$ & $\frac{20 \pm 7^{*}}{(7 \%)}$ & $\begin{array}{c}12 \cdot 1 \pm 3 \cdot 6^{*} \\
\left(327^{\circ} \%\right)\end{array}$ \\
\hline
\end{tabular}

${ }^{*} P<0.001$, compared with respective control value (Student's $t$ test).

\section{Changes in the intratesticular distribution of testosterone (Exp. 5)}

The suggested redistribution of intratesticular testosterone after LH antiserum injection was examined in more detail and the results are illustrated in Text-fig. 1. After antiserum injection, testosterone concentrations in interstitial fluid fell precipitously and progressively such that, by $4 \mathrm{~h}$, levels were reduced by nearly $90 \%$ and by $40 \mathrm{~h}$ by $99 \%$ compared with controls. Seminiferous tubule concentrations of testosterone also fell rapidly within the first $4 \mathrm{~h}$ to $25 \%$ of control levels, but thereafter fell extremely slowly and by $40 \mathrm{~h}$ were $11 \%$ of control values. Confirmation that the rate of decline in testosterone concentrations in the two compartments was different was provided by the ratio of the concentration of testosterone in seminiferous tubules to that in interstitial fluid. At 4 and $8 \mathrm{~h}$ there was a small but significant increase in this ratio and thereafter a progressive increase such that by $40 \mathrm{~h}$ it was increased more than 5-fold compared with controls.

Measurement of the total testicular content of testosterone showed a pattern similar to that of seminiferous tubule testosterone, with more than a $60 \%$ reduction by $4 \mathrm{~h}$ compared with controls, 


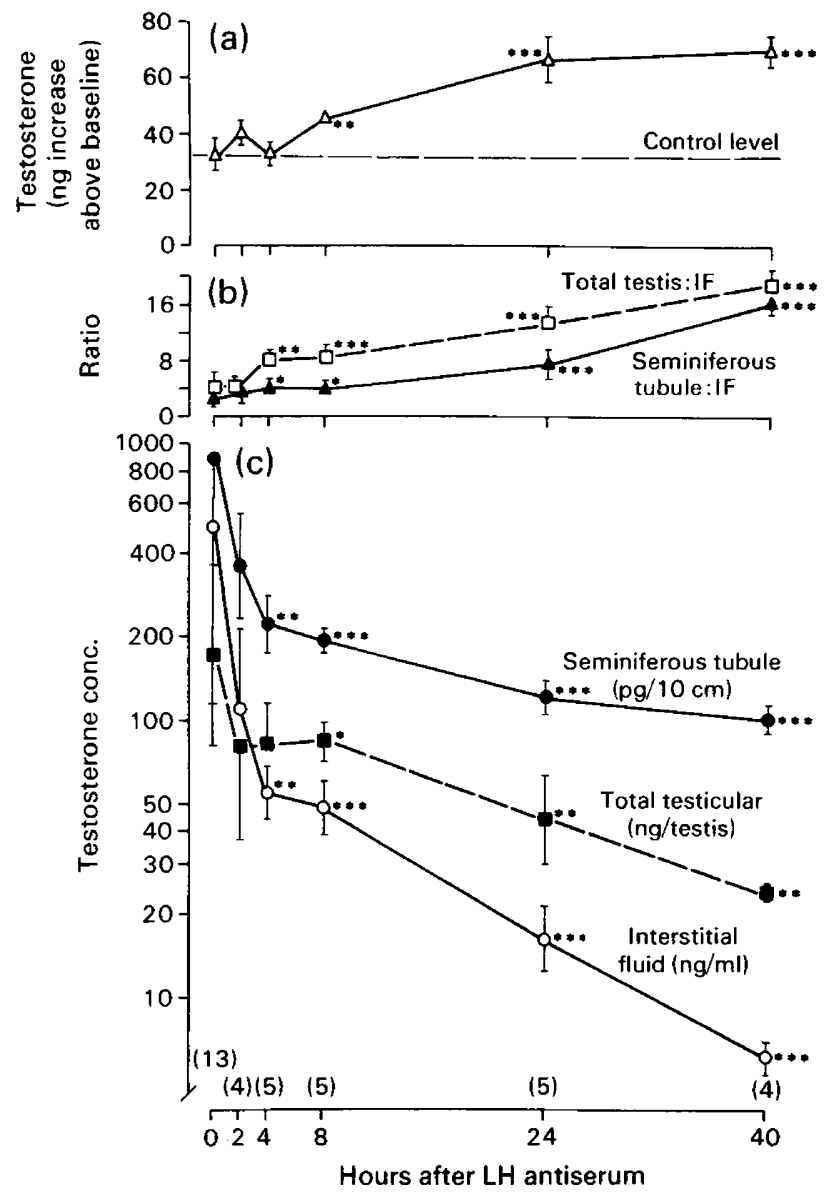

Text-fig. 1. The effect of administration of $\mathrm{LH}$ antiserum on temporal changes in the concentration of testosterone in testicular interstitial fluid (IF) and seminiferous tubules in relation to total testicular content of testosterone (c) and the ability of steroid-free IF to enhance basal testosterone secretion by Percoll-purified Leydig cells (a). Testosterone values are plotted on a logarithmic scale and the ratios of testosterone values in the tubules and whole testis to that in IF are plotted in (b). Each point is the mean \pm s.d. for triplicate incubations (a) or for the number of animals shown in parentheses along the bottom axis (b and c). ${ }^{*} P<0.05,{ }^{* *} P<$ $0.01,{ }^{* * *} P<0.001$, in comparison with the control group (Student's $t$ test).

and values reduced to $11 \%$ of controls at $40 \mathrm{~h}$. Comparison of the ratio of total testicular testosterone to its concentration in interstitial fluid yielded a picture comparable to that of the tubule:interstitial fluid ratio, with values increased significantly at $4 \mathrm{~h}$ followed by progressive increase up to $40 \mathrm{~h}$.

Using the data derived from the Exps 1-5, the relationship between the testosterone concentration in interstitial fluid and seminiferous tubules from individual animals was assessed by plotting the values on a log scale. Over more than a 200 -fold range of values there was an extremely strong positive correlation between testosterone concentrations in the two compartments (Text-fig. 2). However, the regression line relating the two sets of values did not pass through zero, and therefore factors other than the testosterone concentration in interstitial fluid appear to be involved in determining the testosterone concentration within the seminiferous tubule. We therefore tested whether a locally-produced stimulator of testosterone secretion might be important in this respect. 


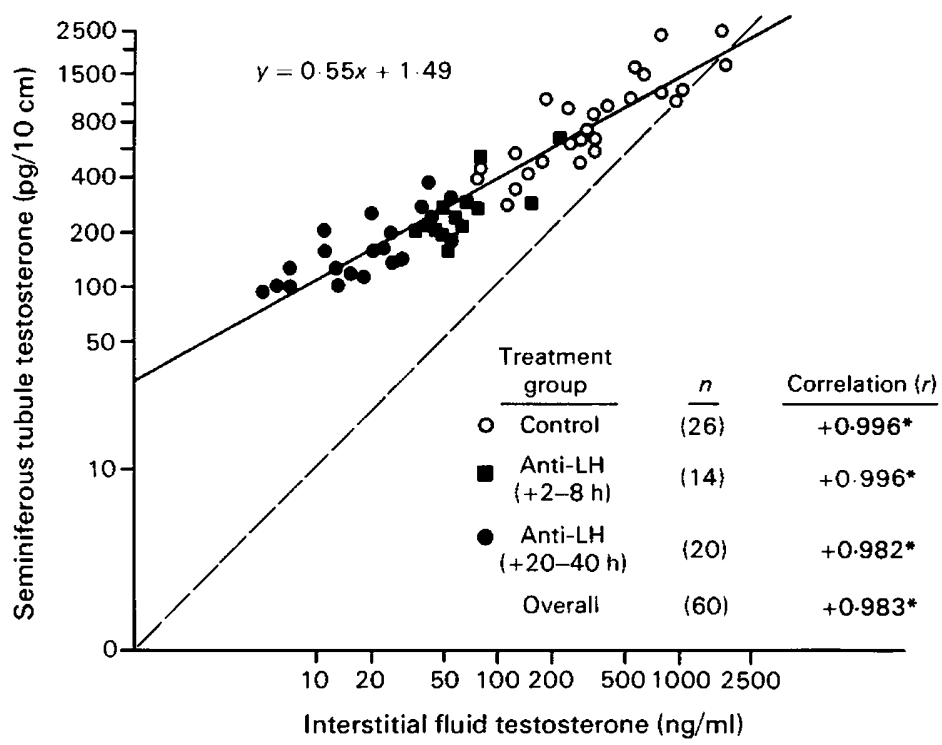

Text-fig. 2. Correlation between testosterone concentrations inside the seminiferous tubules with those outside in testicular interstitial fluid in control rats and rats treated with an LH antiserum. Both sets of values are plotted on a logarithmic scale. The broken line indicates the line of equality whilst the solid line is the best fit calculated by regression analysis of the log values. ${ }^{*} P<0.001$.

Changes in the interstitial fluid levels of a factor which stimulates Leydig cell testosterone secretion (Exps 5-7)

Charcoal-stripped interstitial fluid from the experiment illustrated in Text-fig. 1 was tested for its ability to enhance basal testosterone secretion in vitro by Percoll-purified Leydig cells. Pooled interstitial fluid from control rats caused significant $(P<0.001)$ enhancement of basal testosterone secretion $\left(62 \pm 4 \mathrm{ng} / 10^{6}\right.$ cells) when compared with culture medium alone $\left(28 \pm 3 \mathrm{ng} / 10^{6}\right.$ cells $)$. Pooled interstitial fluid from rats injected 2 or $4 \mathrm{~h}$ previously with antiserum to LH enhanced Leydig cell testosterone secretion to an extent similar to that of fluid from controls (Text-fig. 1). However, at $8 \mathrm{~h}$ after antiserum injection, interstitial fluid enhanced testosterone secretion significantly $(P<0.01)$ more than did control fluid and even larger increases were evident at 24 and $40 \mathrm{~h}$ (Text-fig. 1). The antiserum-induced increase in the ability of interstitial fluid to stimulate Leydig cell testosterone secretion therefore coincided temporally with the highest seminiferous tubule to interstitial fluid testosterone ratios. The difference in the ability of pooled interstitial fluid from control and anti-LH treated rats to enhance hCG-stimulated testosterone production by Leydig cells was evident $(P<0.01)$ at all doses tested over the range $5-30 \%$, and there was no statistically significant $(P<0.05)$ departure from parallelism of the two dose-response curves (data not shown).

When the experiment above was repeated, the ability of interstitial fluid from individual rats to enhance hCG-stimulated testosterone secretion was assessed. Essentially identical results were obtained, namely a significant increase at 8,20 and $40 \mathrm{~h}$ in the ability of the fluid to enhance hCGstimulated testosterone secretion compared with interstitial fluid from control rats (Text-fig. 3). In one group of animals injected $20 \mathrm{~h}$ previously with LH antiserum, injection of $150 \mathrm{i} . \mathrm{u}$. hCG returned interstitial fluid concentrations of testosterone $20 \mathrm{~h}$ later to the upper limit of normal, and coincident with this change there was a marked decrease $(P<0.001)$ in the ability of the interstitial fluid to enhance Leydig cell testosterone secretion when compared with that of $40-\mathrm{h}$ antiserum- 


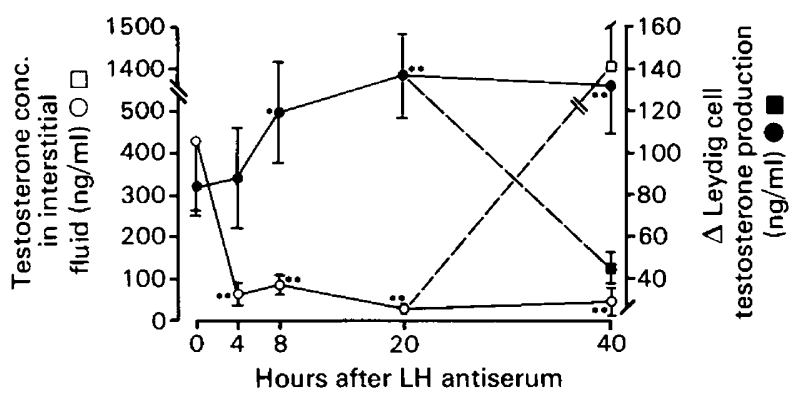

Text-fig. 3. The effect of administration of $\mathbf{L H}$ antiserum on temporal changes in the concentration of testosterone in testicular interstitial fluid and the ability of charcoal-stripped extracts of this fluid to enhance hCG-stimulated testosterone secretion by Percoll-purified rat Leydig cells. At $20 \mathrm{~h}$ after antiserum injection one group of rats was injected with $150 \mathrm{i} . \mathrm{u}$. hCG and killed $20 \mathrm{~h}$ later, and the change in values for these rats is indicated by the square symbols and broken lines. Each point is the mean \pm s.d. for 6 or 7 rats. In assessment of the stimulatory effects of interstitial fluid on steroid production, control testosterone production (i.e. in the absence of IF but in the presence of $5 \mathrm{nM}-\mathrm{hCG}$ ) was $182 \pm 11 \mathrm{ng} / 10^{6}$ cells. ${ }^{*} P<0.05,{ }^{* *} P<$ 0.001 , in comparison with the control group.

treated rats or controls (Text-fig. 3). To test whether this reversal of the effect of LH deprivation by hCG was due to the restoration of high intratesticular values of testosterone, rats were injected with $\mathrm{LH}$ antiserum and at 20 and $28 \mathrm{~h}$ after this treatment were injected with vehicle or $10 \mathrm{mg}$ testosterone propionate and killed at $40 \mathrm{~h}$ after the initial treatment. Injection of testosterone propionate restored normal concentrations of testosterone in both interstitial fluid and seminiferous tubules but failed to attenuate the anti LH-induced increase in the ability of interstitial fluid to enhance hCG-stimulated testosterone secretion in vitro (Table 4).

It is possible that some of the changes in potency of the interstitial fluid reported above, are the result of changes in the total intratesticular volume of interstitial fluid. For example in Exp. 5 there was a significant $(P<0.01)$ decrease in recovered fluid volume at $4 \mathrm{~h}(48 \pm 7 \mu \mathrm{l} /$ testis; mean \pm s.d., $n=5)$ and $8 \mathrm{~h}(48 \pm 13 \mu \mathrm{l})$ after $\mathrm{LH}$ antiserum injection when compared with control values $(76 \pm 18 \mu \mathrm{l} ; n=13)$, although levels were unchanged at $20 \mathrm{~h}(69 \pm 14 \mu \mathrm{l})$ and only slightly

Table 4. Restoration by testosterone propionate of normal interstitial fluid (IF) and seminiferous tubule concentrations of testosterone in rats treated with LH antiserum, and its effect on the ability of IF to stimulate Leydig cell testosterone secretion (mean \pm s.d., $N=5$ )

\begin{tabular}{|c|c|c|c|}
\hline \multirow[b]{2}{*}{$\begin{array}{l}\text { Animal } \\
\text { treatment }\end{array}$} & \multicolumn{2}{|c|}{ Testosterone concentration } & \multirow{2}{*}{$\begin{array}{l}\text { Increment (ng) in Leydig } \\
\text { cell testosterone production } \\
\text { in vitro induced by IF† }\end{array}$} \\
\hline & $\begin{array}{l}\text { In interstitial } \\
\text { fluid }(\mathrm{ng} / \mathrm{ml})\end{array}$ & $\begin{array}{l}\text { In seminiferous } \\
\text { tubules }(\mathrm{pg} / 10 \mathrm{~cm})\end{array}$ & \\
\hline Vehicle & $151 \pm 34$ & $375 \pm 37$ & $221 \pm 35$ \\
\hline Anti-LH & $\begin{array}{c}26 \pm 6^{* * *} \\
(17 \% \text { control })\end{array}$ & $\begin{array}{l}145 \pm 24^{* * *} \\
(39 \% \text { control })\end{array}$ & $332 \pm 51^{* *}$ \\
\hline $\begin{array}{l}\text { Anti-LH } \\
+ \text { testosterone } \\
\text { propionate }(20 \mathrm{mg})\end{array}$ & $\begin{array}{l}141 \pm 39 \\
(93 \% \text { control })\end{array}$ & $\begin{array}{l}432 \pm 92 \\
(115 \% \text { control })\end{array}$ & $350 \pm 61^{* *}$ \\
\hline
\end{tabular}

Rats were injected with saline or anti-LH, and 20 and $28 \mathrm{~h}$ later injected with $10 \mathrm{mg}$ testosterone propionate or vehicle, and then killed $40 \mathrm{~h}$ after the initial treatment.

$\dagger$ Incubations were in the presence of a maximally-stimulating concentration ( $5 \mathrm{nM}$ ) of hCG and testosterone production in the absence of IF was $291 \pm 48 \mathrm{ng} / 10^{6}$ cells.

${ }^{* *} P<0.01,{ }^{* * *} P<0.001$ compared with control (Student's $t$ test). 
decreased at $40 \mathrm{~h}(59 \pm 19 \mu \mathrm{l})$. In Exp. 6, there was again a significant $(P<0.001)$ decrease in the recovered fluid volume at 4 and $8 \mathrm{~h}$ but not at subsequent intervals after LH antiserum injection, and in Exp. 7 no effects of treatment on fluid volume were observed (data not shown).

\section{Discussion}

Our results represent the first study of the quantitative intratesticular distribution of testosterone in situations in which testosterone concentrations have been varied experimentally throughout and below the physiological range. The findings have implications both with respect to the control of intratesticular testosterone levels, and the application of the techniques described to the study of normal and abnormal testicular function. Before considering these aspects, it is necessary to evaluate the validity of the present methods and observations.

In a study of the inter-compartmental distribution of testosterone in the testis, the greatest concern is that the measurement of testosterone may be inaccurate due to its diffusion out of the tissue or between compartments during the preparation of tissue for analysis. The general presumption is that testosterone diffuses readily and rapidly throughout the testis and this prompted us to validate each step of our preparative procedures to minimize this problem. The first concern was that, during the 16-20-h period over which interstitial fluid was normally collected at $4^{\circ} \mathrm{C}$ from the intact testis, diffusion of testosterone out of the tubules into interstitial fluid would occur. Our results demonstrate in 3 ways that this does not appear to happen. First, collection of interstitial fluid by a rapid (30-60 min) method at $4^{\circ} \mathrm{C}$ yielded comparable results to the overnight method. Second, diffusion of testosterone out of intact seminiferous tubules did not occur readily, even during brief $(5 \mathrm{~min}$ ) exposure to physiological temperatures. Third, the observation that the ratio of the concentration of testosterone in seminiferous tubules to that in interstitial fluid was not constant, but could be increased by a factor of 5 or 6 following 20-40 h of LH deprivation argues strongly against the possibility that testosterone diffuses readily from the tubules to interstitial fluid during storage at $4^{\circ} \mathrm{C}$.

Our second concern was that testosterone would diffuse out of the seminiferous tubules during the isolation procedure. However, our experiments in which testicular tissue was dissociated with collagenase at $32^{\circ} \mathrm{C}$ demonstrated that testosterone did not appear to diffuse out of the tubules under these conditions. When tubules were cut into $0.5 \mathrm{~cm}$ lengths diffusion of testosterone out of the tubules then occurred fairly rapidly even at $21^{\circ} \mathrm{C}$, which leads us to conclude that when seminiferous tubules remain in long intact lengths then outward diffusion of testosterone is minimal. This suggests that diffusion is predominantly via the tubular fluid at the cut ends of the tubules rather than across the Sertoli cell and basement membrane. As we chose to perform all stages of the seminiferous tubule dissections at $4^{\circ} \mathrm{C}$ it seems likely that diffusion of testosterone out of the tubules will have been negligible during the the time taken (10-15 min) for dissection of an individual testis, and this concurs with the findings of Parvinen \& Ruokonen (1982). This conclusion is confirmed by our observation that calculation of the sum of the total interstitial fluid testosterone per testis and the total estimated seminiferous tubule testosterone per testis showed little difference from the measured total testosterone content of the extracted contralateral testis.

It is probably because of the steps we have taken to ensure minimal diffusion of intratubular testosterone that the total tubular content of testosterone which we have found represents a considerably higher proportion of the total testicular testosterone than that reported by Podesta $\&$ Rivarola (1974), whilst our results are difficult to compare with other studies (Ruokonen, Vihko \& Niemi, 1973; de Jong et al., 1974; Comhaire \& Vermeulen, 1976) in which testosterone levels in seminiferous tubules were expressed per unit weight of tissue or per ml of seminiferous tubule fluid. Our values for seminiferous tubule testosterone, which ranged in controls from 80 to $2500 \mathrm{pg} / 10 \mathrm{~cm}$, are also generally higher than those $(170-250 \mathrm{pg} / 10 \mathrm{~cm})$ reported by Parvinen \& Ruokonen (1982), whose methods we have essentially followed. However, these authors were performing stage- 
dependent dissections of seminiferous tubules which takes $2-3 \mathrm{~h}$ and involves cutting tubules into 2-mm portions, and it seems likely that such procedures will result in considerably greater loss of testosterone than during our short dissection procedure. The possibility that Leydig cell contamination of the isolated tubules could contribute to the measured testosterone level can also be dismissed as we could detect no significant binding of $\mathrm{hCG}$ to isolated tubules and other studies have revealed no testosterone response of the tubules to hCG during incubation (J. M. S. Bartlett \& R. M. Sharpe, unpublished observations).

Our observation that testosterone concentrations inside and outside the seminiferous tubules were always closely correlated is unequivocal evidence that testosterone concentrations inside the tubules are determined largely by the concentration in interstitial fluid, and this presumably occurs via passive or facilitated diffusion (Setchell, Laurie, Main \& Goats, 1978). However, our results show also that the relationship between testosterone concentrations inside and outside of the seminiferous tubule is not constant and that when testosterone concentrations in interstitial fluid fall to the subnormal range, relatively high levels are maintained in the tubules. More importantly, this relationship was not restricted to this 'artificial' situation, as the relationships between testosterone concentrations inside and outside the seminiferous tubules were log linear over a 200fold range of values (Text-fig. 2), and as testosterone levels in interstitial fluid in control rats fell from high $(1000-2000 \mathrm{ng} / \mathrm{ml})$ to low $(80-200 \mathrm{ng} / \mathrm{ml})$ values, so the tubule :interstitial fluid testosterone ratio increased from around $1 \cdot 0-1 \cdot 5$ to $3 \cdot 0-4 \cdot 0$. These results suggest that intratubular testosterone is somehow restrained from diffusing readily across the tubular wall, thus explaining perhaps some of our in-vitro observations discussed above. The findings could perhaps be explained by the presence of a high-affinity androgen-binding protein (ABP) within the tubules (e.g. Hansson et al., 1976), except that the reported levels of ABP in isolated seminiferous tubules (Ritzen, Boitani, Parvinen, French \& Feldman, 1982) could only account for a minute proportion of the testosterone present in the tubules. Preliminary evidence has indicated the presence of a lowaffinity, high-capacity androgen-binding factor in the seminiferous tubules (Parvinen, 1984), and it is possible that this may help to explain our observations.

Another possibility is that as intratesticular testosterone concentrations decline there is progressive activation of local mechanisms in an attempt to maintain tubular testosterone at a level which can support spermatogenesis (Sharpe, 1984). Just how this could be effected is not known, but the presence of distinct peritubular Leydig cells, coupled with clear evidence for their local regulation by the seminiferous tubules (Bergh, 1982, 1983; see also Sharpe, 1983), demonstrates that such strictly localized effects are potentially feasible. Testicular interstitial fluid from normal rats contains a non-gonadotrophic polypeptide which causes dose-dependent stimulation of both basal and hCG-stimulated testosterone secretion (Sharpe \& Cooper, 1984). This factor is believed to derive from the seminiferous tubules because isolated tubules produce a factor during culture which has identical biological effects on isolated Leydig cells (J. M. S. Bartlett \& R. M. Sharpe, unpublished observations). Our present observation that the levels of this factor in interstitial fluid increase after LH deprivation, and that this increase coincides temporally with the increase in the tubule: interstitial fluid testosterone ratio, raises the possibility that the two events are causally linked. However, there is as yet no evidence to support such a link, and it is possible that other changes, such as alteration of the rate of interstitial fluid turnover (see Setchell \& Sharpe, 1981), could explain or contribute to the changes after LH deprivation. This possibility is supported by the finding that the volume of recovered interstitial fluid decreased significantly at 4 and $8 \mathrm{~h}$ after $\mathrm{LH}$ antiserum injection, although little if any change in volume was observed at 20 and $40 \mathrm{~h}$ when maximal levels of the interstitial fluid factor were evident.

The increase in interstitial fluid levels of this testosterone-stimulating factor after $\mathrm{LH}$ deprivation could not be reversed simply by restoring normal intratesticular values of testosterone which argues against its involvement in a short-loop feedback controlling testosterone supplies to the seminiferous tubules. However, it was reversed by hCG treatment which raised testosterone levels in the testis to the upper limit of the normal range. The latter effect may again implicate 
changes in the turnover of interstitial fluid as the cause or it may indicate the involvement of some other secretory product of the Leydig cells such as $\beta$-endorphin (Margioris, Liotta, Vaudry, Bardin \& Krieger, 1983; Bardin et al., 1984), and experiments to test this possibility are in progress.

In view of the absolute dependence of spermatogenesis on testosterone, the present findings have obvious implications with respect to the regulation of male fertility, particularly in establishing the importance of changes in the intratesticular distribution of testosterone in situations of impaired spermatogenesis.

We thank Irene Cooper for her skilled help, Dr H. M. Fraser for antiserum to LH, Dr Brian Morris for antiserum to testosterone, the NIH hormone distribution program for purified hCG and oLH and the Scottish antibody production unit for normal sheep serum and goat anti-sheep serum.

\section{References}

Ahmad, N., Haltmeyer, G.C. \& Eik-Nes, K.B. (1973) Maintenance of spermatogenesis in rats with intratesticular implants containing testosterone or dihydrostestosterone. Biol. Reprod. 8, 411-419.

Bardin, C.W., Shaha, C., Mather, J., Salomon, Y., Margioris, A.N., Liotta, A.S., Gerendai, I., Chen, C.-L. \& Krieger, D.T. (1984) Identification and possible function of pro-opiomelanocortin derived peptides in the testis. Ann. N.Y. Acad. Sci. (in press).

Bergh, A. (1982) Local differences in Leydig cell morphology in the adult rat testis : evidence for a local control of Leydig cells by adjacent seminiferous tubules. Int. J. Androl. 5, 325-330.

Bergh, A. (1983) Paracrine regulation of Leydig cells by the seminiferous tubules. Int. J. Androl. 6, 57-65.

Buhl, A.E., Cornette, J.C., Kirton, K.T. \& Kuan, Y.D. (1982) Hypophysectomized male rats treated with polydimethylsiloxane capsules containing testosterone: effects on spermatogenesis, fertility and reproductive tract concentrations of androgens. Biol. Reprod. 27, 183-188.

Comhaire, F.H. \& Vermeulen, A. (1976) Testosterone concentration in the fluids of seminiferous tubules, the interstitium and the rete testis of the cat. $J$. Endocr. 70, 229-235.

Corker, C.S. \& Davidson, D.W. (1978) Radioimmunoassay of testosterone in various biological fluids without chromatography. J. Steroid Biochem. 9, 373374.

Cunningham, G.R. \& Huckins, C. (1979) Persistence of complete spermatogenesis in the presence of low intratesticular concentrations of testosterone. Endocrinology 105, 177-186.

de Jong, F.H., Hey, A.H \& van der Molen, H.J. (1974) Oestradiol-17 $\beta$ and testosterone in rat testis tissue: effect of gonadotrophins, localization and production in vitro. J. Endocr. 60, 409-419.

Hansson, V., Weddington, S.C., French, F.S., McLean, W.,Smith, A., Nayfeh, S.N., Ritzen, E.M. \& Hagenas, L. (1976) Secretion and role of androgen-binding proteins in the testis and epididymis. J. Reprod. Fert. Suppl. 24, 17-33.

Margioris, A.N., Liotta, A.S., Vaudry, H., Bardin, C.W. \& Krieger, D.T. (1983) Characterization of immunoreactive pro-opiomelanocortin related peptides in rat testis. Endocrinology 113, 633-641.
Parvinen, M. (1982) Regulation of the seminiferous epithelium. Endocr. Rev. 3, 404-417.

Parvinen, M. (1984) Interactions between germinal cells and Sertoli cells. In Molecular \& Cellular Endocrinology of the Testis. Eds J. Saez \& M. G. Forest. INSERM, Nouzilly (in press).

Parvinen, M. \& Ruokonen, A. (1982) Endogenous steroids in the rat seminiferous tubule. Comparison of the stages of the epithelial cycle isolated by transillumination-assisted microdissection. J. Androl. 3, 211-220.

Podesta, E. J. \& Rivarola, M.A. (1974) Concentration of androgens in whole testis, seminiferous tubules and interstitial tissue of rats at different stages of development. Endocrinology 95, 455-461.

Ritzen, E.M., Boitani, C., Parvinen, M., French, F.S. \& Feldman, M. (1982) Stage-dependent secretion of ABP by rat seminiferous tubules. Molec. cell. Endocr. 25, 25-33.

Ruokonen, A., Vihko, R. \& Niemi, M. (1973) Steroid metabolism in testis tissue. Concentrations of testosterone, pregnenolone and $5 \alpha$-androst-16-en-3 $\beta$-ol in normal and cryptorchid rat testis, and in isolated interstitial and tubular tissue. FEBS Letters 31, 321-323.

Setchell, B.P. \& Sharpe, R.M. (1981) The effect of injected human chorionic gonadotrophin on capillary permeability, extracellular fluid volume and the flow of lymph and blood in the testes of rats. J. Endocr.91, 245-254.

Setchell, B.P., Laurie, M.S., Main, S.J. \& Goats, E.C. (1978) The mechanism of transport of testosterone through the walls of the seminiferous tubules of the rat testis. Int. J. Androl., Suppl., 2, 506-512.

Sharpe, R.M. (1981) The importance of testicular interstitial fluid in the transport of injected hCG to the Leydig cells. Int. J. Androl. 4, 64-74.

Sharpe, R.M. (1983) Local control of testicular function. Q. Jl exp. Physiol. 68, 265-287.

Sharpe, R.M. (1984) Intratesticular factors controlling testicular function. Biol. Reprod. 30, 29-49.

Sharpe, R.M. \& Cooper, I. (1982) The mode of action of LHRH agonists on the rat Leydig cell. Molec. cell. Endocr. 27, 199-211.

Sharpe, R.M. \& Cooper, I. (1983) Testicular interstitial fluid as a monitor for changes in the intratesticular environment in the rat. $J$. Reprod. Fert. 69, 125-135. 
Sharpe, R.M. \& Cooper, I. (1984) Intratesticular secretion of a factor(s) with major stimulatory effects on Leydig cell testosterone secretion in vitro. Molec. cell. Endocr. 37, 159-168.

Sharpe, R.M. \& Fraser, H.M. (1983) The role of LH in regulation of Leydig cell responsiveness to an LHRH agonist. Molec. cell. Endocr. 33, 131-146.
Stevens, R.W. \& Steinberger, E. (1983) Effect of testosterone on quantitative maintenance of spermatogenesis in hypophysectomized rats. Endocrinology 112, Suppl. 175, Abstr. 377.

Wing, T.-Y. \& Christensen, A.K. (1982) Morphometric studies on rat seminiferous tubules. Am. J. Anat. 165, 13-25.

Received 14 September 1984 